\title{
O ARGUMENTO ONTOLÓGICO DE PLANTINGA
}

\section{Plantinga's ONTOLOGicAl ARgument}

Nelson Gonçalves Gomes*

RESUMO - Este artigo apresenta o argumento ontológico de Plantinga, nos seus contextos histórico e sistemático. Críticas ao argumento são também apresentadas. As pretensões filosóficas subjacentes à defesa do argumento são descritas como minimalistas, mas nota-se a sua conexão com um sistema lógico forte.

PALAVRAS-CHAVE - Argumento ontológico. Sistema S5. Argumento ontológico de Plantinga.

ABSTRACT - This article is a presentation of Plantinga's ontological argument in its historical and systematical frames. Criticisms of the argument are presented as well. Philosophical claims underlying the defense of the argument are described as minimalist, but their connection with a strong logical system is noted.

KEYWORDS - Ontological argument. S5 system. Plantinga's ontological argument.

\section{Ecce signum! ${ }^{1}$}

Ao Prof. Dr. Estevão Chaves de Rezende Martins, velho amigo e competente colega.

\section{0 argumento de Anselmo}

Sabidamente, a formulação original do assim chamado argumento ontológico está no Proslógio, de Anselmo de Cantuária (1033-1109), obra

* Universidade de Brasília. <gomes@unb.br>.

1 "Aí está a prova". Expressão tradicional empregada por Shakespeare, Henry IV, Part One, 2.4, fala de Falstaff.

\begin{tabular}{|l|l|l|l|l|l|}
\hline Veritas & Porto Alegre & v. 56 & n. 2 & maio/ago. 2011 & p. 47-63 \\
\hline
\end{tabular}


escrita em torno de 1077, ou seja, no século XI. A versão mais popular desse argumento pode ser apresentada com significativas simplificações. Ponto de partida é a definição de Deus como aquele do qual nada maior pode ser pensado. Nesses termos, Deus deve ser concebido como o Ser Maior, portador de todas as perfeições (bondade, beleza, justiça, etc.) em máximo grau. Cabe, então, a pergunta: pode Deus existir apenas na inteligência do homem? Não! Se Deus existisse só no pensamento humano, seria possível que se pensasse em um outro ser, com todas as propriedades do primeiro, e que, adicionalmente, existisse também na realidade. Ou seja: esse outro ser seria maior do que o primeiro, por ter a existência real como uma perfeição a mais. Nesse caso, entretanto, instala-se uma contradição: Deus é o ser do qual nada maior pode ser pensado, mas é possível pensar-se em outro ser que é maior do que Deus. A simples hipótese de que Deus existe só no pensamento humano conduz a um resultado contraditório, o que prova que ela é falsa. Logo, Deus não pode existir tão somente no pensamento, mas está presente também na realidade (Anselmo, 1973, p. 107-9).

Quando ainda era abade em Bec, na França, Anselmo recebeu de seus monges o pedido de formular um argumento puramente racional para provar a existência de Deus, sem apelo às Escrituras ou a dogmas de fé, mas dotado de conceitos e raciocínios que qualquer pessoa mentalmente sã pudesse entender e admitir. Por isso mesmo, o argumento ontológico tem a pretensão de ser a priori, no sentido de desenvolverse exclusivamente no plano do pensamento. Gaunilo, um monge contemporâneo de Anselmo, obtemperou que a mitológica Ilha Perdida poderia ser pensada, mas sem existir, ao que Anselmo respondeu fazendo notar que a mencionada definição de ser maior aplica-se apenas a Deus e não a ilhas ou a outros objetos contingentes (Ibidem, p. 135-46).

Na Idade Moderna, o argumento ontológico foi retomado em diversos contextos filosóficos racionalistas ou idealistas, nomeadamente, por René Descartes, Baruch de Espinosa, G. W. Leibniz, G. W. Fr. Hegel e outros (Descartes, 1983/III; Espinosa, 1979/I; Leibniz, 1992/IV-cap. X; Hegel, 1984). Sendo a priori, o argumento torna-se muito bem-vindo nessa família de filosofias. Consoante a análise de Röd, o argumento ontológico desempenha um papel filosoficamente crucial em tais sistemas, porquanto ele assume função análoga à das provas de completude nos cálculos axiomáticos contemporâneos (Röd, caps. 2, 3 e 4). Entretanto, a aceitação desse argumento na modernidade não foi unânime, pois Immanuel Kant recusou-o como ilegítimo, por atribuir a Deus a existência como se esta fosse uma propriedade. Com efeito, ser branco, ser pesado e ser mortal, por exemplo, são propriedades, mas o que dizer de existir? Para ser branco, ou pesado, ou mortal um objeto tem de existir, mas isso implica que 
existência é apenas um pressuposto para a atribuição de propriedades, e não uma propriedade. Segundo Kant, o equívoco no tratamento da noção de existência invalida o argumento ontológico (Kant, 1991/III-4ä; Plantinga, 1968, p. 57-64).

\section{Os primeiros argumentos ontológico-modais}

No século XX, o argumento ontológico foi novamente retomado, mas agora em um contexto bem distinto, que é a lógica modal contemporânea. A lógica modal inicia-se na obra de Aristóteles e percorre um longo trajeto até o período da Renascença, quando começa a ser menos estudada. $\mathrm{Na}$ segunda metade do século XVII, Leibniz torna-se um dos poucos a refletir sobre temas modais. Em particular, ele introduz na sua metafísica a importante noção de mundos possíveis: Deus criou este mundo, que é real, mas poderia ter criado outros. Na sua onipotência, Deus poderia ter criado um mundo alternativo no qual o céu fosse verde e não azul; poderia ter criado ainda um terceiro mundo no qual a grama fosse azul e não verde. De um modo geral: Deus criou o mundo real $M_{0}$, mas poderia ter criado os mundos possíveis $M_{1}, M_{2}, M_{3}, \ldots$, em número infinito. O mundo $M_{0}$ e os mundos $M_{1} M_{2} M_{3}, \ldots$ são possíveis, mas só $M_{0}$ é real, enquanto que os demais são meramente possíveis.

Esse repertório leibniziano tem a vantagem de permitir a caracterização de certas frases. A fórmula matemática " $2+2=4$ ", por exemplo, é verdadeira em todos os mundos possíveis, o que a torna logicamente verdadeira. Correspondentemente, " $0=1$ " é falsa em todos os mundos possíveis, o que a faz logicamente falsa. Por fim, uma frase como "O dólar tende a desvalorizar-se", que não é logicamente verdadeira nem logicamente falsa, pode ser descrita como logicamente contingente. No mundo real $M_{0}$, a frase "O céu é azul" é verdadeira, mas pode ser falsa em um mundo alternativo $M_{1}$, no qual o céu seja verde. No contexto desse tipo de reflexão, é admissível que uma frase seja verdadeira em um mundo possível, mas falsa em outro. O filósofo que trabalha com a noção de mundos possíveis tem de pensar as suas questões em diferentes mundos. Em especial, ao tratar da noção de um Ser Supremo, ele indagará sobre Deus no mundo $M_{0}$, ou no mundo $M_{1}$ e assim por diante. Qualquer passagem de um mundo para outros não é óbvia e deve ser justificada. Um filósofo que empregue lógica modal tem de enfrentar a questão sobre a possibilidade de Deus existir em um mundo possível, mas não em outros.

Coube ao filósofo norte-americano Clarence Irving Lewis (1883-1964), em 1912, iniciar um trabalho que conduziria à formação da lógica modal contemporânea. Em uma lógica desse tipo, consideram-se frases como, 
por exemplo, "Necessariamente, $2+2=4$ ", ou "É impossível que $0=1$ ", ou "É possível que o dólar tenda a desvalorizar-se". Consoante esses exemplos, a expressão "necessariamente" deve ser anteposta a frases verdadeiras em todos os mundos possíveis, enquanto que "é impossível" convém a enunciações sempre falsas e "é possível" a asserções por vezes verdadeiras. Em 1932, Lewis apresenta a série de sistemas modais S1, S2, S3, S4 e S5, na qual "S" representa a palavra inglesa "strict" (Lewis \& Langford, 1932/1959, p. 492-502). Nessa série, o sistema S5 é o menos estrito, o mais simples e também o mais forte, em termos de prova, mesmo que sob pressupostos filosóficos controversos. Isso porque, nos sistemas S1, S2, S3, S4, as noções de necessidade e possibilidade são correlacionadas de diversas maneiras restritas. No contexto de S5, porém, prova-se que todos os mundos possíveis estão ligados por uma relação universal, de tal maneira que aquilo que for necessário, impossível ou possível em um deles será também necessário, impossível ou possível em todos os demais. Em outras palavras, visto que a frase "Necessariamente, $2+2=4$ " é verdadeira no mundo real $M_{0}$, ela será igualmente verdadeira em $M_{1}, M_{2}, M_{3}, \ldots$ Grosso modo, o sistema S5 contém as intuições leibnizianas sobre as modalidades. Em S5, a transposição de verdades de um mundo para outro é mais fácil do que em qualquer dos sistemas que lhe são anteriores, razão por que os argumentos ontológicos são nele mais facilmente expressos.

A teoria dos mundos possíveis revelou-se filosoficamente fecunda. No seu contexto, foi possível caracterizar, por exemplo, a noção de propriedade essencial: se Sócrates for racional em todos os mundos possíveis nos quais ele esteja presente, então a racionalidade será uma propriedade essencial de Sócrates. Se Sócrates for canhoto em um mundo possível, mas destro em outro, então tais propriedades ser-lhe-ão contingentes e não essenciais. Cabe notar que, em um mundo possível no qual os seus pais jamais se tenham encontrado, Sócrates estará ausente, razão por que a existência de Sócrates é contingente.

No argumento ontológico formulado por Alvin Plantinga (1932- ), a ser aqui apresentado, trabalha-se com essa noção: uma essência é uma propriedade essencial ou é aquilo que envolve todas as propriedades essenciais de determinado ente. Nesses termos, se a racionalidade, a corporeidade e a mortalidade forem suas propriedades essenciais, então uma essência de Sócrates será algo que, de alguma maneira, unifica e acarreta todas essas propriedades, no sentido de que onde estiver Sócrates, aí estarão as suas racionalidade, corporeidade e mortalidade. Tal conceito de essência deve ser entendido em uma acepção rigorosamente individualizante, pois uma essência de Sócrates não pode ser partilhada por nenhum outro ente, em nenhum mundo possível (Plantinga, 1974/1982, 
pp. 70 et seq.). Por si só, tal noção de essência não é parte de S5, mas sim é um adendo metafísico introduzido por Plantinga.

No século XX, o argumento ontológico é formulado, por várias vezes, com o auxílio do sistema S5, o que é uma nova forma de abordagem de significativa importância. Em 1941, Charles Hartshorne (1897-2000) publica a sua versão do argumento, na qual emprega o conceito de insuperável grandeza de Deus (Hartshorne, 1941). Hartshorne, um norte-americano egresso de Harvard, que, nos anos 1920, estuda na Alemanha com Edmund Husserl e Martin Heidegger, é o mais profícuo filósofo a investigar o argumento ontológico em todo o século passado, mas apenas em 1962 ele apresenta uma forma amadurecida do seu argumento (Hartshorne, 1962). Vale a pena enfatizar que Hartshorne provém de Harvard, a universidade na qual C. I. Lewis trabalhara e onde desenvolvera as suas pesquisas em lógica modal. Apesar do seu pioneirismo, o citado ensaio de 1941 teve pouca repercussão à época.

Em 1960, Norman Malcolm (1911-1990), um norte-americano que vem a estudar com Ludwig Wittgenstein em Cambridge e dele torna-se amigo, formula um novo argumento ontológico no contexto de S5. Para evitar objeções de tipo kantiano, Malcolm faz uso de uma estratégia engenhosa. Supostamente baseado em Anselmo, ele afirma o seguinte: não se deve dizer que existência seja uma perfeição, mas sim que a impossibilidade lógica da não existência é uma perfeição. Em outras palavras: existência necessária é uma perfeição (Malcolm, 1960). Desde a sua formulação, o argumento de Malcom foi vivamente discutido e, por extensão, trouxe à baila as ideias precursoras de Hartshorne.

\section{0 argumento ontológico de Plantinga²}

Em dois trabalhos de 1974, Alvin Plantinga formula uma versão do argumento ontológico baseada em S5, mas dotada de estratégias mais amplas e sofisticadas do que aquelas empregadas pelos seus antecessores (Plantinga 1974 e 1974/1982). De maneira especial no seu livro The Nature of Necessity, Plantinga desenvolve toda uma ampla e complexa teoria modal que, em particular, abriga o argumento ontológico, razão por que ele é um modalista de significativa importância.

Quem pensa sobre a existência de Deus no contexto de mundos possíveis enfrenta uma questão que não ocorre em outros ambientes filosóficos: pode Deus existir em alguns mundos possíveis e não em outros? É levando em conta esse peculiar tipo de pergunta que Plantinga critica

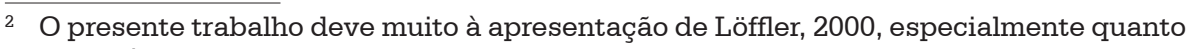
ao capítulo 6 dessa obra. 
os argumentos de Hartshorne e Malcolm. Segundo Plantinga, o Ser Maior tratado nos textos destes últimos não é aquele cultuado pelos crentes, pois quem adora o Ser Supremo não se interessa por uma entidade excelente neste mundo $M_{0}$, mas fraca, ignorante e ruim talvez em $M_{1}$ ou em $M_{2}$. Além disso, a existência necessária, em si mesma, não é um sinônimo adequado de grandeza, pois o número 7 existe em todos os mundos possíveis, o que não acontece com Sócrates. Não obstante, seria errôneo dizer que, no mundo real $M_{0}$, aquele número excede Sócrates em grandeza (Ibidem, 212 et seq.). Para escapar a críticas como aquelas formuladas por Kant, Plantinga admite que existência não é uma propriedade, mas tão somente uma condição para que se possa ter propriedades.

A estratégia de Plantinga introduz um novo conceito, que é a noção de propriedades mundo-indexadas (world-indexed properties), a ser esclarecida por meio de um exemplo. Suponha-se que Sócrates seja destro no mundo real $M_{0}$. Nesse caso, ser destro é uma propriedade acidental de Sócrates, pois ele pode ser canhoto em $M_{1}$. Não obstante, em todos os mundos nos quais ele existe, Sócrates tem a propriedade de ser destro em $\mathrm{M}_{0}$, de modo que esta última é mundo-indexada. Como essa é uma propriedade que ocorre em todos os mundos nos quais ele está presente, ser destro em $\mathrm{M}_{0}$ é uma propriedade essencial de Sócrates e, por definição, é acarretada por uma essência desse filósofo (Ibidem, p. 62 et seq.). A distinção entre ambos os tipos de propriedades é importante: ser destro não é mundo-indexada, mas ser destro em $\mathrm{M}_{0}$ sim.

Ao invés de trabalhar com a noção usual de insuperável grandeza de Deus, Plantinga subdivide-a em partes, pois introduz dois novos conceitos: excelência máxima de uma essência, em um mundo $\mathrm{M}$ e grandeza máxima de uma essência. As propriedades que os sistemas teístas tradicionalmente atribuem a Deus (onipotência, onisciência e perfeição moral) perfazem a excelência máxima, que Plantinga não entende como mundo-indexada, pois é possível que um ente tenha excelência máxima apenas em $M_{0}$, por exemplo. Essa propriedade, entretanto, não deve ser confundida com ter excelência máxima em $\mathrm{M}_{0}$, que é mundo-indexada. Portanto, ter excelência máxima não é propriedade essencial. A grandeza máxima de uma essência, entretanto, é a excelência de um ser no mundo real $M_{0}$ e em todos os demais mundos possíveis $M_{1}, M_{2}, M_{3}, \ldots$, o que a torna uma generalização da excelência máxima (Ibidem, p. 213-4).

Uma vez estabelecidos tais conceitos, dois postulados são estabelecidos na base do argumento:

A. A propriedade grandeza máxima implica estritamente excelência máxima em qualquer mundo possível;

B. A propriedade excelência máxima implica estritamente onipotência, onisciência e perfeição moral. 
O postulado (A) caracteriza o conceito de grandeza máxima como generalização da excelência. Dizer que a primeira implica estritamente a segunda significa que onde está aquela está esta, em qualquer mundo possível. A asserção (B), por sua vez, caracteriza o que seja excelência máxima. Embora tal propriedade não seja mundo-indexada, (B) estabelece que onde quer que haja excelência máxima tem de haver onipotência, onisciência e perfeição moral.

Os postulados (A) e (B), por si sós, não garantem que as propriedades ter grandeza máxima e ter excelência máxima estejam exemplificados em algum mundo possível. Na verdade, (A) e (B) limitam-se a definir que relações existem entre essas propriedades. Uma vez estabelecidos tais elementos, o núcleo do argumento de Plantinga pode ser formulado graças à introdução de um terceiro postulado:

C. É possível que a grandeza máxima esteja exemplificada.

$\mathrm{Na}$ linguagem de $\mathrm{S} 5$, esse postulado significa que:

a. existem um mundo $\mathrm{M}$ e uma essência $\mathrm{E}$, tais que, E está exemplificada em $\mathrm{M}$, sendo que $\mathrm{E}$ implica estritamente ter grandeza máxima em M.

Portanto, em ao menos um mundo possível $M$, existe um ser $X$ com a propriedade ter grandeza máxima em $\mathrm{M}$.

Plantinga representa uma concepção bastante específica a respeito da natureza dos mundos possíveis, cujos pormenores não entram diretamente na presente prova, salvo quanto a um ponto: ele remete aqueles mundos ao mundo real. Isso leva-o a pressupor, implicitamente, a hipótese de que $M$ seja o mundo real. Esse pressuposto tácito pode ser explicitado por meio da seguinte hipótese:

h. seja $\mathrm{M}=\mathrm{M}_{0}{ }^{3}$

Ora, consoante o postulado (A), o ser $X$ tem excelência máxima em qualquer mundo possível no qual ele exista. Logo, em $M$, a seguinte frase é logicamente verdadeira e, portanto, necessária:

b. Para qualquer entidade X, vale: se X exemplifica a essência E, então $\mathrm{X}$ exemplifica a propriedade ter excelência máxima em qualquer mundo possível.

Porém, neste contexto de S5, o que é necessário num mundo é-o em todos. Portanto, a frase (b) é necessária em todos os mundos possíveis. Daí conclui-se o seguinte:

3 Esse pressuposto implícito torna-se claro por meio do linguajar de Plantinga, que fala dos mundos possíveis nos seguintes termos: Se $M$ fosse o mundo real... (If $W^{*}$ had been actual...) Plantinga, 1974/1982, p. 215. 
c. a essência E implica estritamente a propriedade ter excelência máxima em qualquer mundo possível.

Ora, não tem sentido falar de um ser $X$ como portador de uma propriedade em determinado mundo possível, se $X$ nele não existe ${ }^{4}$. Logo,

d. a essência $E$ implica a condição de existir em qualquer mundo possível.

A partir daí, conclui-se:

e. Se M é um mundo possível, é impossível que a essência E não esteja nele exemplificada.

Ao formular esta frase (e), Plantinga libera-se da hipótese (h), pois dela ele não é mais precisa ${ }^{5}$. Nesse contexto de S5, o que é impossível em um mundo é impossível em todos. Nesses termos, é impossível que $X$ não exista em todos os mundos possíveis. Por conseguinte, considerando-se o estabelecido em (B), tem-se a conclusão final:

f. Em todos os mundos possíveis, existe um ser maximamente excelente, ou seja, onipotente, onisciente e moralmente ótimo, que é Deus.

g. Em particular, Deus existe no mundo real $\mathrm{M}_{0}$.

A conclusão ( $g$ ) é mero corolário da frase (f). Com isso, o argumento está completo (Ibidem, p. 213-217).

A estratégia de Plantinga consiste em admitir que a mencionada essência $E$ está exemplificada em ao menos um mundo possível. A partir daí, apoiado sobre as suas definições, postulados e sobre algumas propriedades do sistema S5, ele generaliza a asserção do postulado (C) e conclui que o ser maximamente excelente, isto é, Deus, existe em todos os mundos possíveis e, portanto, também no mundo real $M_{0}$.

Sob forma negativa e bastante simplificada, o argumento de Plantinga deixa-se resumir da seguinte forma:

Admitam-se os postulados (A), (B). Se em nenhum mundo possível $M$ existe um ser $X$ dotado da propriedade ter grandeza máxima, então tal propriedade não é implicada por nenhuma essência. Logo, sob tais postulados, com inclusão de $(\mathrm{C})$, se o ser $X$ tem a referida propriedade em ao menos um mundo possível, então existe uma essência de $X$, ou seja, $E$, que implica a propriedade ter excelência máxima em todos os mundos possíveis e neles efetivamente existir. Logo, esse $X$ é Deus, que existe não apenas em alguns mundos, mas em todos e também no real.

4 Plantinga, 1974/1982, pp. 149-52 e p. 214.

5 Se a hipótese (h) é liberada, ela deixa de fazer parte do argumento, cujas conclusões remontam, então, apenas aos três postulados. Em geral, em sistemas dedutivos, hipóteses são premissas provisórias, a serem descartadas assim que cumprem o seu papel. 
Essa conclusão pode ser deduzida com o auxílio de S5, desde que definições e postulados do gênero admitido por Plantinga sejam adicionadas ao referido sistema. S5 é apenas a lógica subjacente, de maneira que a conclusão metafísica inferida por Plantinga não seria dedutível sem a inclusão dos referidos postulados e definições, igualmente metafísicos.

\section{Um argumento mais simples}

O argumento acima apresentado perfaz o núcleo da teologia filosófica de Plantinga, mas há dele uma versão simples que o próprio autor propõe. Essa versão pode ser descrita de maneira próxima à anterior, o que será feito a seguir.

Postulados básicos:

A'. A seguinte proposição é logicamente verdadeira e, portanto, necessária: Um ser tem grandeza máxima se, e somente se, ele tem excelência máxima em qualquer mundo possível.

B'. A seguinte proposição é logicamente verdadeira e, portanto, necessária: Qualquer ser que tenha excelência máxima é onipotente, onisciente e moralmente perfeito.

Estabelecidas essas asserções, introduz-se uma novidade, que é a definição de propriedade universal: $P$ é uma propriedade universal se, e somente se, $P$ está exemplificada em qualquer mundo possível ou em nenhum.

Por exemplo, ser uma pessoa em qualquer mundo é uma propriedade universal, pois ou um indivíduo $X$ tem tal propriedade em $M_{0}, M_{1}, M_{2}$, $M_{3}, \ldots$, ou $X$ não é pessoa em mundo nenhum, pois seria absurdo que $X$ tivesse essa propriedade apenas em alguns mundos. Por outro lado, ser um homem canhoto não é uma propriedade universal, pois um indivíduo $X$ pode tê-la em $M_{0}$, mas não em $M_{1}$.

A versão simplificada exige o seguinte postulado adicional:

C'.Existe um mundo possível, no qual a propriedade ter grandeza máxima está exemplificada.

Dados os postulados e a definição, deduz-se o que vem a seguir.

a'. Consoante a asserção (A'), as propriedades ter grandeza máxima e ter máxima excelência são equivalentes, isto é, elas envolvem o mesmo valor de verdade (verdadeiro ou falso) em qualquer mundo possível.

b'. A propriedade ter máxima excelência em qualquer mundo é propriedade universal. Por conseguinte, em virtude da equivalência, ter insuperável grandeza também o é. 
C'. Conforme o postulado (C'), a propriedade ter grandeza máxima está exemplificada, em um mundo possível $M$.

d'. Logo, como propriedade universal, ela está exemplificada em todos os mundos possíveis $M_{0}, M_{1}, M_{2}, M_{3}, \ldots$, de maneira que, em todos eles, há um ser onipotente, onisciente e moralmente excelente, que é Deus.

e'. Corolário: estando presente em todos os mundos, Deus está presente também no mundo real.

Neste ponto, a prova simplificada está completa (Ibidem, p. 216).

Löffler dá o nome de Princípio de Anselmo à tese de que a existência de Deus é necessária ou impossível. Segundo ele, em todos os argumentos ontológicos esse princípio tem um papel crucial (Löffler, 2000, p. 91 et seq.). A presente versão simplificada oferece um exemplo claro do emprego do Princípio de Anselmo, na medida em que a propriedade ter insuperável grandeza deve estar exemplificada em todos os mundos possíveis ou em nenhum. Mais uma vez, a estratégia do argumento consiste em assumir tão somente a premissa da mera possibilidade de que Deus esteja em um mundo, pois, nesse caso, está igualmente em todos, o que torna necessária a referida presença. Nos quadros descritos por Plantinga, o argumento permite uma transição restrita da possibilidade à necessidade. Como na resposta de Anselmo a Gaunilo, as definições de grandeza e excelência constantes no argumento de Plantinga tornam Deus um caso particular, no qual a mera possibilidade implica necessidade.

Ao início do século 18, Leibniz critica Descartes, pois este teria provado tão somente a conexão entre a possibilidade da existência de Deus, de um lado, e a respectiva necessidade, de outro. Entretanto, segundo Leibniz, Descartes teria deixado de provar que a existência de Deus é possível, falha essa que o próprio Leibniz se julgava em condições de sanar (Leibniz, 1992, IV, cap. 10). No argumento de Plantinga, vê-se que a prova da necessidade a partir da possibilidade é aparentada com as ideias de Leibniz.

Embora Plantinga apresente o seu próprio argumento como vitorioso, ele reconhece algumas dificuldades acarretadas pelo tipo de definições que formula. Plantinga menciona, dentre outros, o conceito não ter maximalidade, a ser definido da seguinte maneira: o objeto $X$ não tem maximalidade se, e somente se, não existe um ser dotado de grandeza máxima. Claramente, não ter maximalidade e ter grandeza máxima são propriedades mutuamente incompatíveis, no sentido de que se uma delas está exemplificada, então a outra não está. Apesar dessa dificuldade, Plantinga afirma a racionalidade das premissas subjacentes às duas versões do seu argumento, pois é racional supor a possibilidade de um 
ser dotado de grandeza máxima, porquanto isso simplifica a teologia (Plantinga, 1974/1982, p. 219 et seq.).

\section{As objeções lógico-filosóficas de Grim}

Em 1984, o lógico Patrick Grim dirige contra Plantinga uma bemhumorada crítica de conteúdo, que pode ser resumida na célebre frase do pintor espanhol Francisco de Goya: O sonho da razão produz monstros ${ }^{6}$. Segundo Grim, é possível que se obtenham resultados bizarros por meio de simples adaptações do argumento de Plantinga. Graças a esse método, deduz-se, dentre outros absurdos, a existência de um ser maximamente ignorante. A dedução é a seguinte:

1a. É possível que haja um ser maximamente ignorante.

1b. Logo, existe um mundo possível no qual a máxima ignorância está exemplificada.

2. Necessariamente, alguém é maximamente ignorante se, e somente se, é maximamente desinformado em qualquer mundo.

3. Necessariamente, em qualquer mundo possível, alguém é maximamente desinformado se, e somente se, existe em qualquer mundo.

4. Em ao menos um mundo possível, a seguinte frase é impossível: Não existe nenhum ser maximamente desinformado.

5. Ora, o que é impossível em um mundo, é-o em todos.

6. Logo, no mundo real e em todos os demais, existe um ser maximamente desinformado.

Grim entende que o seu argumento é plenamente análogo ao de Plantinga, de modo que o caráter absurdo daquele implica o absurdo deste. Segundo Grim, empregando precisamente a mesma analogia argumentativa, seria possível provar até mesmo a existência de entidades mutuamente contraditórias. O seguinte exemplo é interessante como ilustração da ideia de Grim. Tome-se a definição de duende vermelho especial nos seguintes termos: em todo mundo possível, duende vermelho especial é um duende sem nenhuma outra cor, mas capaz de destruir outros duendes quaisquer, embora não possa ser destruído por nenhum deles. Um duende verde especial tem definição análoga. Pois bem, segundo Grim, a partir da primeira definição, é possível a prova da existência de duendes vermelhos especiais. A partir da segunda, prova-se a existência dos

6 "El sueño de la razón produce monstruos". Em espanhol, a palavra "sueño" significa sono e também sonho, o que possibilita duas interpretações para a citada frase: a) o descanso da razão, isto é, o seu não exercício, conduz a monstros; b) o delírio da razão leva a monstros. A frase é de 1799 e está na água-forte de número 43, na série de Goya intitulada Los Caprichos. 
correspondentes duendes verdes. Ao fim e ao cabo, em todos os mundos possíveis, estão caracterizados duendes que podem e não podem destruir outros duendes e ser por eles destruídos.

A refutação de Grim consiste em uma espécie de redução ao absurdo, pois, se ele está correto, a forma de raciocinar sugerida por Plantinga conduziria à possibilidade de que o discurso da razão viesse a incluir na população do universo uma infinidade de seres monstruosos (Grim, 1984).

\section{As objeções metalógicas de Mackie}

Independentemente das suas objeções ao argumento de Plantinga, Mackie é um detrator do sistema S5, que ele considera arbitrário. A preferência de Mackie dirige-se a uma concepção modal alternativa sugerida por Prior, segundo a qual o mundo $M_{0}$ pode ser entendido como base a partir da qual múltiplos mundos possíveis seriam definidos ${ }^{7}$. Analogamente, um mundo meramente possível $M_{1}$ seria base de outra série de mundos, etc. Nos termos dessa proposta, a proposição que for logicamente verdadeira na série de mundos constituída sobre $M_{0}$ seria verdadeira para os mundos dessa mesma série e não para os mundos agrupados sobre $M_{1}$. Em um sistema assim entendido, não seria admissível o princípio segundo o qual o possível é sempre necessariamente possível, conhecido como Axioma S5. Com efeito, a partir desse axioma, provase que uma proposição possivelmente necessária é mesmo necessária, enquanto que, no sistema preferido por Mackie, uma proposição pode ser possivelmente necessária, mas sem tornar-se necessária (Mackie, 1982, p. 55-7).

Além de criticar S5, Mackie acusa Plantinga de nele gerar problemas complementares, na medida em que define as mencionadas propriedades mundo-indexadas, pois, graças a elas, os mundos possíveis passariam a depender uns dos outros. Sem entrar em pormenores técnicos, Mackie considera que a aceitação de tais propriedades acarreta o abandono de uma importante característica de S5, que consiste na eliminação de todas as sequências de operadores modais anteriores a uma proposição, salvo no último caso. Por exemplo, se $p$ é uma proposição, $\mathrm{N}$ é a expressão modal "necessariamente" e P é "possivelmente", então PPNNPNp é uma fórmula que, no sistema $\mathrm{S} 5$, é redutível a $\mathrm{Np}$, pois, tirante a expressão mais próxima a $p$, os demais operadores podem ser cancelados. Ora, no

7 Mackie usa a expressão "'nested' set of possible worlds" ("conjunto 'aninhado' de mundos possíveis") para designar a série de mundos definida sobre a base $M_{0}$, por exemplo (Mackie, 1982, p. 57). 
sistema preferido por Mackie, esse cancelamento não ocorre. Mais uma vez, sem entrar em minudências quanto à sua afirmação, Mackie diz que S5 não é o sistema adequado para o tipo de argumento desenvolvido por Plantinga (Ibidem, p. 57).

Mackie reconhece que o argumento ontológico de Plantinga é válido, nas duas formas apresentadas mais atrás. Não obstante, ele analisa criticamente os postulados (C) e (C'), indagando se, de facto, a exemplificação da propriedade ter grandeza máxima é possível. Em sua ajuda, Mackie chama o testemunho do próprio Plantinga, que reconhece a legitimidade da definição de conceitos como não ter maximalidade ou de ter maximalidade aproximada, por exemplo, que são rivais de ter grandeza máxima. Daí vem a pergunta de Mackie: por que preferir este àqueles? Ele entende que a eventual circunstância de uma escolha aconselharia a preferência pelos referidos conceitos rivais, porquanto eles têm, pelo menos, a vantagem de maior flexibilidade. Se o conceito ter maximalidade aproximada está exemplificado em $M_{0}$, possivelmente ter excelência máxima pode estar igualmente exemplificado em $M_{1}$ (ibidem, p. 58-63). Em contraposição a isso, a propriedade ter grandeza máxima é inflexível.

Mackie faz ver que o próprio Plantinga se cinge a afirmar em termos mínimos a racionalidade do seu argumento. Ele cita uma passagem na qual este reconhece que o argumento não tem o êxito esperado na teologia natural, mas que a afirmação do postulado de tipo (C) é admissível, daí decorrendo validamente a respectiva conclusão (Ibidem, p. 57-8).

\section{As objeções epistemológicas de Tomberlin}

A última questão tratada nas críticas de Mackie é retomada por Tomberlin, cuja objeção contra Plantinga tem a ver com a suposta racionalidade do teísmo. Segundo Tomberlin, uma opção racional deveria envolver boas razões capazes de levar alguém a escolher esta proposição e não aquela, sob pena de não existir conhecimento justificado. Ora, se a aceitação de postulados como $(C)$ ou $\left(C^{\prime}\right)$ não tem tal característica, em que medida ela é racional? Em outras palavras, se a aceitação de um postulado teísta tem o mesmo peso que a admissão de um pressuposto ateu, qual é a vantagem filosófica do teísmo sobre o ateísmo? (Tomberlin, 1985, p. 265 et seq.).

A resposta de Plantinga a Tomberlin retoma o seu minimalismo já presente em The Nature of Necessity: a posição teísta é racional negativamente, ou seja, na medida em que não é irracional. Crer que a propriedade ter grandeza máxima pode estar exemplificada não é irracional, mesmo se quem crê não tem maior justificativa em favor de tal 
proposição e mesmo que outros não a admitam. Quem afirma a tese teísta está no âmbito do seu direito epistêmico (Plantinga, 1985, p. 385).

O minimalismo de Plantinga quanto ao seu argumento, na verdade, deixa-se estender à sua concepção de filosofia. Segundo ele, quem aceita a definição de Leibniz para a identidade ou rejeita as leis clássicas da distribuição, ao sistematizar a mecânica quântica, está no seu direito epistêmico, mesmo que outros pensem diferentemente. Em filosofia, procurar por segurança levaria o pensador a restringir-se à regra do modus ponens ou a coisas do gênero. Plantinga admite mesmo que o seu raciocínio talvez não seja uma prova da existência de Deus, mas insiste em dizer que ele é um argumento racional, ou seja, não irracional, em favor dessa tese (Plantinga, 1974/1982, p. 219-21).

\section{Avaliação}

$\mathrm{O}$ que dizer do contra-argumento apresentado por Grim? Embora engenhoso, ele não é propriamente novo, pois Michael Tooley e Stephen Read formularam argumentos referentes ao demônio que lhe são análogos (Tooley, 1981, Read, 1981, ambos apud Xavier, 2011, p. 264-5). Cabe observar que objeções dessa ordem podem ser levantadas também contra o argumento original de Anselmo, que tolera a construção de raciocínios rivais, mas estruturalmente idênticos, em favor da existência do mal insuperavelmente pensável. Como diz Xavier, a posição anselmiana não evita o dualismo, mas objeções como as de Tooley e Read não constituem o raciocínio mais forte contra a versão de Anselmo para o argumento ontológico (Xavier, 2011, p. 267). Mutatis mutandis, o mesmo pode ser afirmado com respeito ao raciocínio de Grim, cujos postulados carecem de cuidadosa análise crítica, o que não necessariamente o torna um sério contraexemplo para o argumento de Plantinga.

As objeções de Mackie perdem algo da sua força por duas razões. Primeiramente, ele recusa in limine o sistema S5, que Plantinga toma como lógica subjacente. Em segundo lugar, ele apenas afirma que as definições e raciocínios de Plantinga são incompatíveis com S5 ou que tornam inaplicáveis certas propriedades desse sistema, mas não oferece uma prova tecnicamente desenvolvida para tais asserções. Como filósofo, Mackie pode criticar S5, mas tem de levar em conta que esse sistema é consistente e completo, o que o torna plenamente elegível como lógica subjacente.

A crítica de Mackie, entretanto, tem um ponto bastante forte, quando ele pergunta pela razão da escolha em favor de postulados como (C) ou $\left(C^{\prime}\right)$. Por que não escolher postulados rivais de caráter ateu? As objeções de Tomberlin vão na mesma direção, pois trata-se de saber se o teísmo é 
capaz de apresentar o porquê das sua opções. A resposta de Plantinga, como consta mais atrás, é marcadamente minimalista: a opção teísta é racional na medida em que não é irracional; ao postular $(C)$ ou ( $\left.C^{\prime}\right)$, o teísta faz uso do seu direito epistêmico.

O argumento de Plantinga é válido? Sim, no sentido usual da expressão: se as premissas forem verdadeiras, a conclusão também o será. O argumento é um bom raciocínio em termos de teologia racional ou de filosofia da religião? Não, na medida em que os postulados do argumento não são mais fortes do que a respectiva conclusão ${ }^{8}$. Nesse sentido, o argumento de Plantinga, embora válido, é um argumento fraco.

É comum, embora controversa, a distinção entre argumentos válidos, bons e fortes. Mas, sejam lá quais forem as definições adotadas, é certo que o argumento de Plantinga milita fracamente em favor do discurso teísta, embora possa ser tomado como débil indício da sua racionalidade. Nessa acepção, o pedido dos monges de Bec não é atendido, pois o argumento não se apoia sobre postulados que qualquer criatura racional poderia aceitar, excluídas considerações rivais.

Ao discorrer sobre filosofia para justificar as suas posições minimalistas quanto ao seu argumento, Plantinga despoja-se de quaisquer pretensões à segurança epistêmica, no que ele se contenta com a não irracionalidade do próprio discurso. Essa posição, entretanto, tem um aspecto singular, pois o mencionado minimalismo de pretensões epistêmicas subjaz a um argumento formulado no contexto do sistema S5, que é o mais forte dentre os sistemas padrão. Se Plantinga escolhesse S4 ou os sistemas que lhe são anteriores, o argumento não poderia ser formulado, por falta da relação universal entre mundos possíveis, que só se dá em S5. Portanto, o mínimo de pretensões filosóficas combina-se com o máximo de suposições lógicas.

Os mencionados raciocínios de Hartshorne, Malcolm e Plantinga não são os únicos a serem formulados com o auxílio de S5, porquanto Kurt Gödel (1906-78) também apresentou um argumento ontológico do mesmo tipo, elaborado em termos axiomáticos (Gödel, 1995). O argumento de Gödel é controverso e tem características específicas que o distinguem dos anteriores (Gomes, 2006). Não obstante, ele preserva traços cruciais encontradiços em todos os argumentos ontológicos, em particular, a incorporação do Princípio de Anselmo. Em geral, os argumentos ontológicos baseados em S5 são raciocínios válidos, mas permanece em aberto a pergunta pelo seu caráter de verdadeiras provas.

8 Em um simpósio de filosofia da religião realizado na Universidade de Brasília, em agosto de 2011, Plantinga reconheceu que as premissas do seu argumento estão por demais próximas da conclusão. 
N. G. Gomes - O argumento ontológico de Plantinga

\section{Referências}

ANSELMO, 1973. Proslógio. Tradução de Ângelo Ricci. Volume Santo Anselmo/ Abelardo, Coleção "Os Pensadores", VII, 1a edição. São Paulo: Abril Cultural, p. 101-46. DESCARTES, René, 1983. Meditações. Volume Descartes, Coleção "Os Pensadores", 3ạ edição. São Paulo: Abril Cultural, p. 73-212.

ESPINOSA, Baruch de, 1979. Ética. Volume Espinosa, Coleção "Os Pensadores", $2^{\mathrm{a}}$ edição. São Paulo: Abril Cultural, p. 71-302.

GOMES, Nelson G., 2006. Summum Bonum. Analytica, vol. 10, n. 1, p. 43-105.

GÖDEL, K, 1995. Ontological Proof. Collected Works, vol. III. S. Feferman \& S. C. Kleene (eds.). New York: Oxford University Press, p. 403-4 e p. 476.

GRIM, Patrick, 1984. Gremlins Revenged: Gremlins Repulsed. Philosophical Studies (Irlanda), 30, p. 33-42.

HARTSHORNE, Charles, 1941. Man's Vision of God and the Logic of Theism. New York: Willet, Clark \& Company.

HARTSHORNE, Charles, 1962. The Logic of Perfection and Other Essays in Neoclassical Metaphysics. La Salle: Open Court.

HEGEL, G. W. Fr. 1984. Vorlesungen über die Philosophie der Religion. W. Jaeschke (Hrsg.). Hamburg: Meiner Verlag.

KANT, I, 1991. Crítica da razão pura. Volume II Kant. Coleção "Os Pensadores", $4^{a}$ edição. São Paulo: Nova Cultural.

LEIBNIZ, G. W. 1992. Novos ensaios sobre o entendimento humano. Volume II Leibniz. Coleção "Os Pensadores", 5a edição. São Paulo: Nova Cultural, p. 09-232.

LEWIS, C. I. \& LANGFORD, C. H. 1932/1959. Symbolic Logic. New York: Dover Publications, Inc, 1a edição 1932, 2 ${ }^{\mathrm{a}}$ edição 1959.

LÖFFLER, Winfried, 2000. Notwendigkeit, $S_{5}$ und Gott - Das Ontologische Argument für die Existenz Gottes in der zeitgenössischen Modallogik. Münster: LIT.

MACKIE, John Leslie, 1982. The Miracle of Theism: Arguments for and against the Existence of God. Oxford: Clarendon Press.

MALCOLM, Norman, 1960. "Anselm's Ontological Argument". The Philosophical Review 69, p. 41-62.

PLANTINGA, Alvin, 1968. The Ontological Argument - from St Anselm to Contemporary Philosophers. London - Melbourne: Macmillan.

PLANTINGA, Alvin, 1974. God, Freedom and Evil. Grand Rapids: Eerdmans Publishing Co. PLANTINGA, Alvin 1974/1982. The Nature of Necessity. Oxford: Oxford University Press, 1a edição 1974, reimpressão 1982.

PLANTINGA, Alvin 1985. Replies. Alvin Plantinga. TOMBERLIN, James E. \& VAN INWAGEN, Peter (eds.), 1985, p. 313-96.

READ, Stephen, 1981. Reflections on Anselm and Gaunilo. International Philosophical Quarterly, vol. XXI, n. 4, p. 437.

RÖD, Wolfgang, 1992. Der Gott der reinen Vernunft - Die Auseinandersetzung um den ontologischen Gottesbeweis von Anselm bis Hegel. München: Beck. 
TOMBERLIN, James E., 1985. Plantinga and the Ontological Argument. Alvin Plantinga. TOMBERLIN, James E. \& VAN INWAGEN, Peter (eds.), 1985, p. 257-70.

TOMBERLIN, James E. \& VAN INWAGEN, Peter (eds.), 1985. Alvin Plantinga. Dordrecht - Boston - Lancaster: D. Reidel Publishing Company.

TOOLEY, Michael, 1981. Plantinga's Defense of Ontological Argument. Mind, vol XC, no 359, p. 425.

XAVIER, Maria Leonor L. O. 2011. A questão do argumento ontológico. Philosophica (Lisboa). 37, p. 241-70. 